\title{
A course for recently appointed consultants
}

\author{
Judy Harrison and Francis Creed
}

\begin{abstract}
Becoming a consultant is often viowed as the finci hurdte in our lengthy protessional troining. Yet the consultiont role carries with it additional responsibilities and streseses for which the recent copointee may foel ithprepared. This paper describes a two-day course for recently appointed consultont poychlatilsts. Feedback from the 24 attenders suggested the course was greatty valued.
\end{abstract}

With the National Health Service (NHS) reforms, the seemingly endless flood of government directives and the move to community care, the pressures faced by consultant psychiatrists continue to escalate. Recent research suggests that stress levels among psychiatrists are among the highest within the medical profession (FirthCozens, 1995). Senior registrar training in psychiatry is increasingly structured and coherent but may not prepare the trainee for becoming a consultant. Additional support and training should therefore be targeted at those who have recently taken up consultant posts, in order to ease their progression through this transitional period. One way of doing this is to run courses specifically aimed at the recently appointed consultant.

\section{The course}

The Untversity Department of Psychiatry in Manchester has been running a two-day course for newly appointed consultant psychiatrists for several years. The course generally attracts about 20 consultants who are within the first two years of their appointment. The aims of the course are to identify common problems and stresses faced by newly appointed consultants and to share and develop ways of coping with these pressures. In March 1995, 24 consultants attended from across the United Kingdom. The content of the four main sessions is described.

\section{Job plans, diaries and time management}

Prior to attending the course, the participants were asked to keep a detalled diary for one working week, dividing their time into hours of direct patient contact, clinical meetings, patient related administration, non-patient related administration, teaching and supervision, travel, research and breaks. The results were fed back to individuals with their own use of time compared to the median and range for the whole group.

Despite wide variation in job descriptions, the figures showed remarkable similarities both within the group and with previous course attenders (Creed, 1995). A relatively low proportion of time (median 13 hours), was spent in face to face patient contact, with a similar period of time spent on total administration, of which about half was directly patient related (letters, telephone calls, etc).

This information was used as the basis for a role-play, in which a service manager negotiated with two consultants to agree the job plan for a new consultant post. The manager insisted that the new post involve more fixed sessions for outpatient clinics and direct patient contact than previously while the consultants were keen to preserve the need for flexibility within the week and time set aside for administration.

All groups managed to reach agreement on the job plan although the concessions varied. The pressures from managers to increase direct patient contact had to be balanced against the need for flexibility within the week and time set aside for administration. In some cases, the managers agreed to provide extra resources such as community psychiatric nurses (CPNs), computers or audit clerks in exchange for a modest increase in consultant activity.

\section{Dealing with anxieties}

A second half-day workshop explored the anxdeties experienced by recently appointed consultants. These included the expectation that consultants are experts with a ready solution for all situations, the difficulties of managing other people, including multidisciplinary teams, junior staff and colleagues, and the responsibility of providing services with inadequate resources. Other common stresses included the competing demands of work and family life, a sense of powerlessness when change cannot be achieved 
Table 1. Ways of dealing with job stress

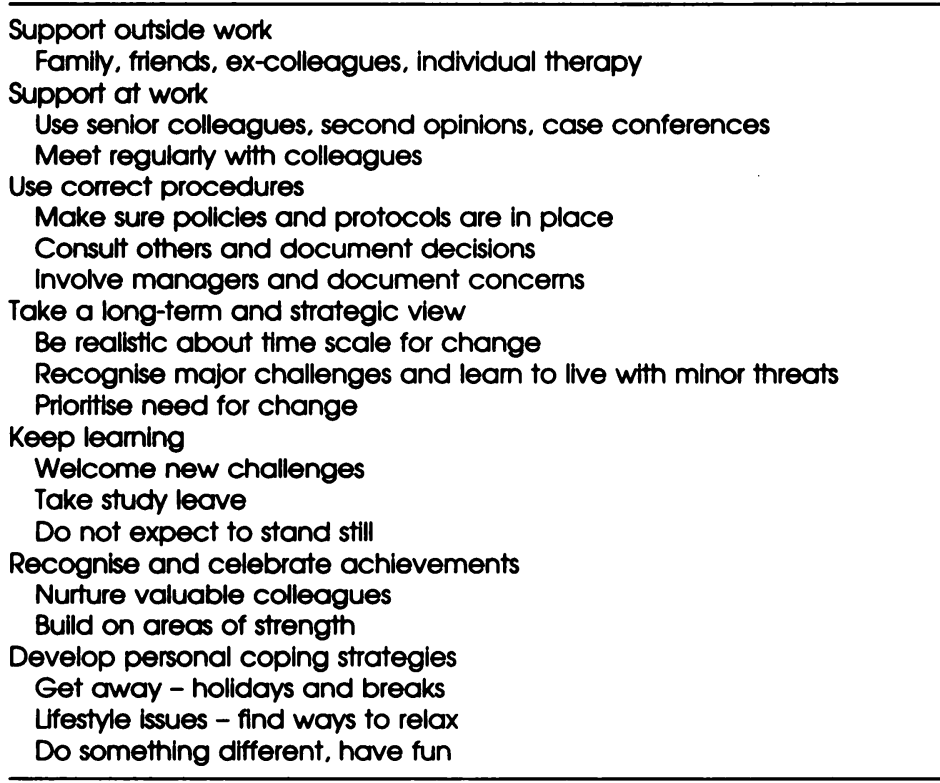

and fear of burning out. Lack of support is a common experience, particularly if consultant colleagues are all considerably older. In group discussion, a number of ways of dealing with these pressures were identified (Table 1).

\section{Multidisciplinary team meetings}

A common anxiety-provoking situation is the multidisciplinary team meeting. During one session, the consultants were asked to role-play a team meeting with video feedback. Each participant was asked to play a somewhat caricatured member of the team with one reluctant volunteer playing the consultant. Following the role-play, the power relationships and alliances within the team were discussed. The uses of personal, position and tactical power were compared and the participants were asked to comment on their experiences within the role-play. The benefits of analysing group processes in order to manage multidisciplinary groups were evident. The course feedback showed this to be the most popular session.

\section{Planning for the future}

Medical training encourages us to be largely reactive rather than to think in a strategic or proactive way. Perhaps for the first time, newly appointed consultants have the opportunity to influence the way in which their service is organised, but may not have the experience to know how to initiate or manage change.

Through small group discussions, the consultants were asked to identify areas for personal, professional and service development. These were listed in three categories: changes achieved in the last 12 months, changes proposed in the next 12 months and changes proposed for the following two to four years. Most of the consultants felt they had already achieved some changes and had a clear idea of how they wanted their service to develop. They also identified a variety of specific professional challenges which they wished to achieve over the next few years. These ranged from training in psychotherapy, family therapy and computers, to acquiring management skills and becoming a Royal College examiner. The consultants were encouraged to review progress with these challenges in the future and to continue to set personal and professional objectives.

\section{Supporting newly appointed consultants}

At the end of the course, a session was spent looking at ways of reducing the difficulties faced by newly appointed consultants through changes in senior registrar training and in the first months of the consultant post.

At senior registrar level practical management experience needs to supplement theoretical 
courses. This could include shadowing consultants with a management role, attending management meetings, discussing management issues in consultant supervision, managing part of a service for a period of time and undertaking consultant locums.

For newly appointed consultants, an induction period is helpful, with reduced patient load. This should be negotiated at the time of appointment and should include the opportunity to spend time in all parts of a service. New consultants may need to organise this themselves but should consult with those already in post about who to visit. The use of mentors for newly appointed consultants was also suggested. This might be a senior colleague who undertakes to meet with the new appointee on a regular basis during the first few months to discuss any difficulties encountered. New and established consultants should also endeavour to change the culture to make it more acceptable to talk about job pressures and seek help from others.

Ongoing training and education were also emphasised. Newly appointed consultants should be encouraged to make full use of their study leave and to register with the College for Continuing Professional Development.

\section{Feedback}

Feedback from the course was uniformly positive and all the participants had some plans for personal change. These included better organisation (37\%), time management $(42 \%)$ and management of secretaries (42\%), setting personal objectives (17\%), protecting time for professional training and education (21\%), obtaining additional support from peers or others $(21 \%)$, being more positive and celebrating achievements (12\%) and being less nice to others (4\%)!

\section{Summary}

Considerable time and energy are spent on the training of psychiatrists. At present these efforts appear to cease abruptly on becoming a consultant, despite the fact that this is a particularly stressful transition. Perhaps the greatest benefit from the course described was the opportunity to meet with colleagues in a similar position in order to share challenges and offer support and solutions. The popularity of this course suggests it should not be an isolated training event.

\section{Acknowledgements}

With thanks to Dr Graeme McGrath and Dr Frank Margison for their continued input to the running of the course.

\section{Reference}

CREed, F. (1995) How consultants manage their time. Advances in Psychiatric Treatment, 1, 65-70

FIRTH-CozENS, J. (1995) Stress in Doctors: A Longitudinal Study. Research report commissioned by the Department of Health. Research and Development Initiative on Mental Health of the NHS Workforce.

*Judy Harrison, Consultant Psychiatrist and Francis Creed, Professor of Psychiatry, Manchester Royal Infirmary, Oxford Rd, Manchester M13 9WL

*Correspondence 